\title{
RANCANG BANGUN ALAT UKUR SUHU DAN KADAR ALKOHOL MENGGUNAKAN SENSOR LM35 DAN SENSOR MQ-3
}

\author{
Dolpfy Latupeirissa $^{1)}$, Verna A. Suoth ${ }^{1)}$, Hesky S. Kolibu ${ }^{1)}$ \\ ${ }^{1)}$ Program Studi Fisika, FMIPA Universitas Sam Ratulangi Manado \\ email: dolpfy $0701 @$ yahoo.com; vernasuoth@yahoo.co.id; heskystevy@yahoo.com
}

\begin{abstract}
ABSTRAK
Telah dilakukan penelitian untuk membuat alat ukur suhu dan kadar alkohol menggunakan sensor LM35 dan sensor MQ-3. Sistem akuisisi data alat ukur suhu dan kadar alkohol menggunakan mikrokontroler ATMega8 dan data hasil akuisisi ditampilkan menggunakan LCD $2 \times 16$. Alat ukur diuji dan dibandingkan dengan alat ukur standar. Hasil pengujian menunjukkan alat ukur suhu dan kadar alkohol dapat mengukur perubahan suhu dengan akurat dengan nilai NRMSE 0,0028, dan dapat mengukur kadar alkohol untuk alkohol medis dengan kadar 60\%-90\% dan alkohol aren dengan kadar 35\%-55\%.
\end{abstract}

Kata kunci: suhu, kadar alkohol, sensor LM35, sensor MQ-3

\section{DESIGN AND CONSTRUCTION OF TEMPERATURE AND ALCOHOL CONTENT MEASURING INSTRUMENT USING LM35 SENSOR AND MQ-3 SENSOR}

\begin{abstract}
A research has been conducted to make temperature and alcohol content measuring instrument using LM35 sensor and MQ-3 sensor. Data acquisition system of temperature and alcohol content measuring instrument was using ATMega8 microcontroller and data acquisition result were displayed using $2 \times 16$ LCD. Measuring instrument was tested and compared with standard measuring instruments. Test result shows that temperature and alcohol content measuring instrument could measure temperature changing with NRMSE valued 0,0028 and could measure alcohol content for medical alcohol with $60 \%-90 \%$ alcohol content and aren palm alcohol with $35 \%-55 \%$ alcohol content.
\end{abstract}

Keywords: temperature, alcohol content, LM35 sensor, MQ-3 sensor

\section{PENDAHULUAN}

Pengukuran merupakan kegiatan yang dilakukan untuk menentukan nilai suatu besaran dari suatu objek. Pengukuran menjadi dasar dari sebagian besar aktfitas manusia. Berbagai instrumen pengukuran juga telah menjadi bagian yang lekat dalam aktifitas kehidupan manusia. Pengukuran juga adalah dasar dari penelitian ilmiah dan industrial (Placko, 2007).

Destilasi adalah teknik untuk memisahkan larutan ke dalam masing-masing komponennya. Prinsip destilasi didasarkan atas perbedaan titik didih komponen zatnya. Destilasi dapat digunakan untuk memurnikan senyawa-senyawa yang mempunyai titik didih berbeda sehingga dapat dihasilkan senyawa yang memiliki kemurnian yang tinggi. Karena prinsip destilasi didasarkan pada perbedaan titik didih komponen larutannya, maka dalam proses destilasi, suhu menjadi salah satu faktor penentu. Pengukuran dan pengaturan suhu dalam proses destilasi, menentukan tingkat kemurnian produk destilasi yang akan dihasilkan. Seperti dalam proses destilasi alkohol, persentase kemurnian alkohol yang akan dihasilkan dapat ditentukan dengan pengaturan suhu pada proses pemanasan bahan baku. 
Penelitian ini bertujuan untuk mendesain dan mengkonstruksi alat ukur suhu dan kadar alkohol menggunakan sensor suhu LM35 dan sensor gas alkohol MQ-3 untuk dapat digunakan sebagai alat ukur dalam proses destilasi alkohol.

\section{TINJAUAN PUSTAKA}

\section{Destilasi}

Destilasi adalah teknik untuk memisahkan larutan ke dalam masing-masing komponennya. Prinsip destilasi adalah didasarkan atas perbedaan titik didih komponen zatnya. Destilasi dapat digunakan untuk memurnikan senyawa-senyawa yang mempunyai titik didih berbeda sehingga dapat dihasilkan senyawa yang memiliki kemurnian yang tinggi. Proses destilasi dilakukan dengan mengeluarkan komponen dengan titik didih yang lebih rendah dari larutan dengan cara menguapkan komponen tersebut (Kister, 1992).

\section{Sistem Pengukuran}

Pengukuran adalah aktifitas yang selalu dibutuhkan dalam kehidupan seharihari. istem pengukuran berfungsi menyediakan informasi tentang nilai suatu besaran dari objek yang diukur. Menurut Bolton (2006) sistem pengukuran terdiri dari sensor, prosesor sinyal dan penampil data. Sensor adalah elemen yang secara efektif berhubungan dengan proses dimana suatu variabel sedang diukur dan menghasillkan keluaran dalam bentuk tertentu tergantung pada variabel masukannya. Prosesor sinyal adalah elemen yang mengambil keluaran dari sensor dan mengubahnya menjadi suatu bentuk besaran yang cocok untuk tampilan atau transmisi selanjutnya dalam beberapa sistem kontrol. Penampil data adalah elemen yang menampilkan nilai-nilai yang terukur dalam bentuk yang bisa dikenali oleh pengamat.

\section{Sensor LM35}

Sensor suhu LM35 adalah komponen elektronika yang memiliki fungsi untuk mengubah besaran suhu menjadi besaran listrik dalam bentuk tegangan. LM35 adalah sensor suhu yang mudah digunakan dengan linearitas yang sangat baik dan bisa digunakan dengan rangkaian eksternal minimal dengan jenis penerapan yang luas.
LM35 adalah sensor suhu yang teliti dimana tegangan keluaran sensor sangat linear berpadanan dengan perubahan suhu, yakni 10 $\mathrm{mV} /{ }^{\circ} \mathrm{C}$. Sensor yang digunakan dalam penelitian ini adalah sensor LM35D dengan jangkauan pengukuran suhu $0^{\circ} \mathrm{C} 100^{\circ} \mathrm{C}$.

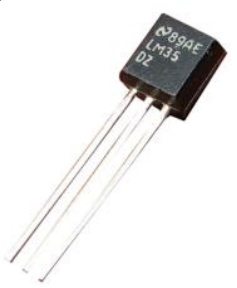

Gambar 1. Sensor Suhu LM35

\section{Sensor MQ-3}

Sensor MQ-3 memiliki material sensitif berupa lapisan $\mathrm{SnO} 2$ yang konduktifitasnya rendah di udara bersih. Konduktifitas sensor semakin naik sebanding terhadap konsentrasi gas alkohol di udara. Dibandingkan sensor alkohol lainnya, sensor MQ-3 memiliki harga yang lebih murah dengan sensitifitas yang mirip, namun konsumsi dayanya lebih besar, yakni sekitar $750 \mathrm{~mW}$ (Satria, 2013). Sensor ini digunakan untuk menangkap kandungan uap alkohol yang menguap dari cairan yang akan dideteksi. Semakin banyak kandungan uap alkohol yang terdeteksi maka resistansi sensor akan menjadi semakin kecil. sehingga tegangan keluaran sensor menjadi semakin besar.

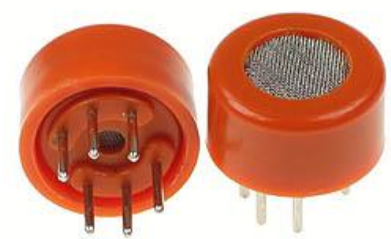

Gambar 2. Sensor Alkohol MQ-3

\section{Pengkondisi Sinyal}

Sinyal-sinyal listrik yang dihasilkan oleh sensor harus dikonversi ke dalam bentuk yang dikenali oleh sistem akuisisi data yang dipakai. Tugas pengkondisi sinyal yang sering dilakukan adalah penguatan. Selain itu pengkondisi sinyal bisa juga melakukan penapisan sinya. Misalnya pengkondisi sinyal dengan penapis lolos-rendah digunakan untuk meloloskan sinyal dengan frekuensi rendah dan menahan sinyal dengan frekuensi tinggi.

Operasional amplifier (Op-Amp) atau penguat operasional adalah suatu penguat berpenguatan tinggi yang terintegrasi dalam 
sebuah chip IC yang memiliki dua input, inverting dan non-inverting dengan sebuah terminal output, dimana rangkaian umpan balik dapat ditambahkan untuk mengendalikan karakteristik tanggapan keseluruhan pada penguat operasional. Penguat tak membalik (non-inverting amplifier) merupakan penguat sinyal dengan karakteristik dasar sinyal output yang dikuatkan memiliki fasa yang sama dengan sinyal input.

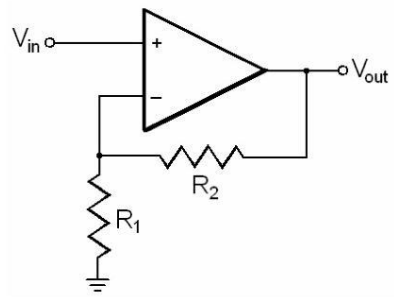

Gambar 3. Non-Inverting Amplifier

Besarnya penguatan tegangan output dari rangkaian penguat tak membalik dituliskan dalam persamaan sebagai berikut.

dengan

$$
A_{V}=\frac{R_{2}}{R_{1}}+1
$$

$A_{V}=$ penguatan tegangan

$R_{1}=$ hambatan resistor $1(\Omega)$

$R_{2}=$ hambatan resistor $2 /$ feedback $(\Omega)$

\section{Mikrokontroler AVR ATmega8}

AVR merupakan salah satu jenis mikrokontroler yang di dalamnya terdapat berbagai macam fungsi. Kelebihan dari AVR adalah memiliki Power-On Reset, yaitu tidak perlu ada tombol reset dari luar karena cukup hanya dengan mematikan daya, maka secara otomatis AVR akan melakukan reset.

AVR ATmega8 adalah mikrokontroler CMOS 8-bit berarsitektur AVR RISC yang memiliki 8 Kbyte In-System Programmable Flash. Mikrokontroler dengan konsumsi daya rendah ini mampu mengeksekusi instruksi dengan kecepatan maksimum 16MIPS pada frekuensi $16 \mathrm{MHz}$.

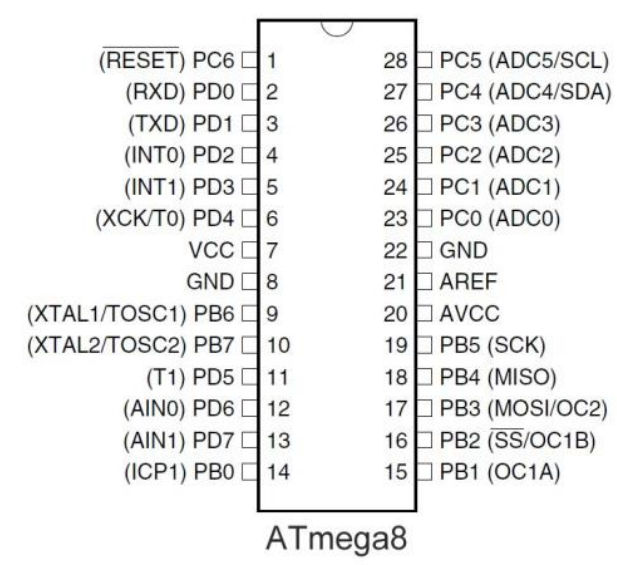

Gambar 4. Konfigurasi Pin AVR ATMega8

\section{Analog to Digital Converter}

Analog to Digital Converter (ADC) adalah pengubah input analog menjadi kodekode digital. ADC banyak digunakan sebagai pengatur proses industri, komunikasi digital dan rangkaian pengukuran/pengujian. Prinsip kerja ADC adalah mengkonversi sinyal analog ke dalam bentuk besaran yang merupakan rasio perbandingan tegangan input dan tegangan referensi seperti pada persamaan berikut.

dengan

$$
N=\frac{V_{\text {in }}}{V_{\text {ref }}}\left(2^{n}-1\right) \quad \ldots \ldots
$$

$N$ = data dalam biner (bit)

$V_{\text {in }}=$ tegangan input $(\mathrm{mV})$

$V_{\text {ref }}=$ tegangan referensi $(\mathrm{mV})$

$n \quad=$ jumlah bit/resolusi (bit)

\section{$L C D$}

Display elektronik adalah salah satu komponen elektronika yang berfungsi sebagai tampilan suatu data, baik karakter, huruf ataupun grafik. LCD (Liquid Cristal Display) adalah salah satu jenis display elektronik yang dibuat dengan teknologi CMOS logic yang bekerja dengan tidak menghasilkan cahaya tetapi memantulkan cahaya yang ada di sekelilingnya terhadap front-lit atau mentransmisikan cahaya dari back-lit. LCD berfungsi sebagai penampil data baik dalam bentuk karakter, huruf, angka ataupun grafik. Dalam modul LCD terdapat mikrokontroler yang berfungsi sebagai pengendali tampilan karakter LCD yang dilengkapi dengan memori dan register. 


\section{METODOLOGI PENELITIAN}

Penelitian dimulai dengan pembuatan desain rangkaian alat ukur suhu dan kadar alkohol. Kemudian dilakukan pembuatan rangkaian pengkondisi sinyal untuk sensor LM35 dan sensor MQ-3. Rangkaian sensor dan pengkondisi sinyal kemudian disatukan dengan rangkaian sistem minimum mikrokontroler ATMega8 dan LCD. Pengkondisi sinyal sensor LM35 dan sensor MQ-3 dikalibrasi agar sesuai dengan ADC yang terprogram dalam mikrokontroler ATMega8. Setelah itu dilakukan pengujian pengukuran pengukuran suhu dan pengukuran kadar alkohol menggunakan alat ukur suhu dan kadar alkohol dan hasil pengujian dibandingkan dengan hasil pengukuran menggunakan alat ukur pembanding.

\section{HASIL DAN PEMBAHASAN}

\section{Rancangan Alat}

Alat ukur suhu dan kadar alkohol dirancang seperti gambar berikut.

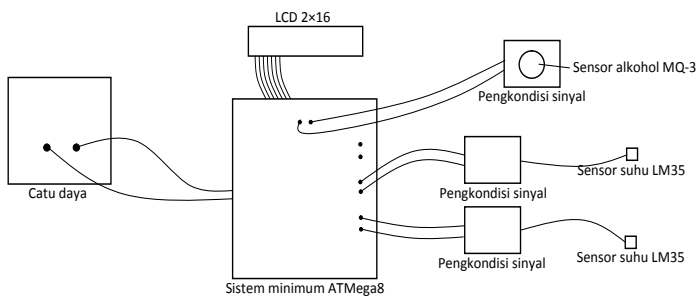

Gambar 5. Rancangan Alat Ukur Suhu dan Kadar Alkohol

Sensor LM35 akan mendeteksi perubahan suhu dan sensor MQ-3 akan mendeteksi konsentrasi alkohol. Pengkondisi sinyal akan menyesuaikan tegangan dari sensor yang masuk ke mikrokontroler untuk diproses menjadi data. Data hasil keluaran mikrokontroler akan ditampilkan melalui LCD.

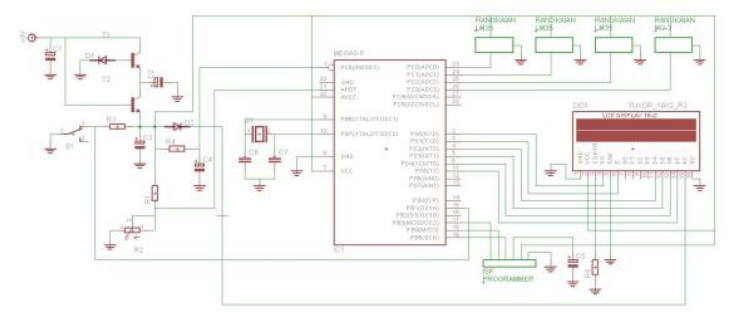

Gambar 6. Diagram Skematik Alat Ukur Suhu dan Kadar Alkohol
Rangkaian sistem minimum mikrokontroler ATMega8 dan LCD yang digunakan memiliki diagram skematik dalam Gambar 6.Pengkondisi sinyal sensor LM35 dibuat sesuai diagram skematik Gambar 7.

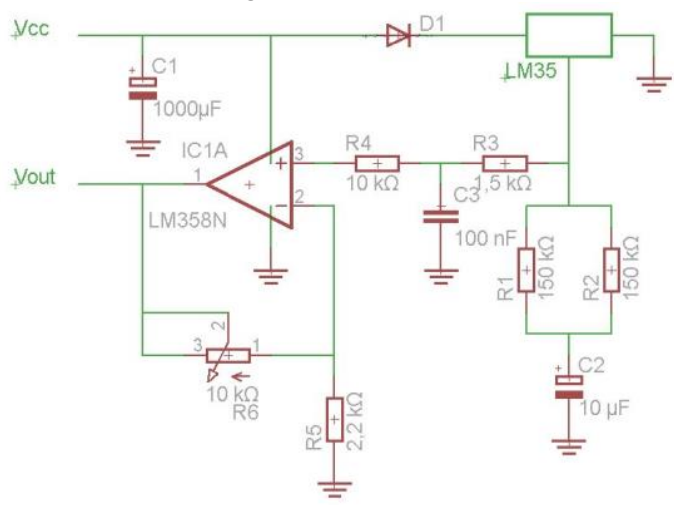

Gambar 7. Diagram Skematik Pengkondisi Sinyal Sensor LM35

Dua buah resistor $150 \mathrm{k} \Omega$ dirangkai secara paralel membentuk rangkaian dengan resistansi $75 \mathrm{k} \Omega$ dirangkai secara seri dengan kapasitor $10 \mu \mathrm{F}$. Resistor $1,5 \mathrm{k} \Omega$ dan kapasitor $100 \mathrm{nF}$ membentuk rangkaian low pass filter untuk menjaga kestabilan keluaran sensor LM35. Tegangan keluaran filter diumpankan ke non-inverting amplifier dengan nilai penguatan yang dapat diubah sesuai pengaturan besar resistansi resistor variabel.

Pengkondisi sinyal sensor MQ-3 dibuat sesuai diagram dalam Gambar 8.

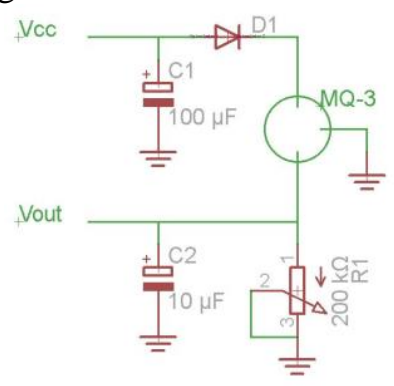

Gambar 8. Diagram skematik pengkondisi sinyal sensor MQ-3

Sensor MQ-3 dirangkai dengan resistor variabel $200 \mathrm{k} \Omega$ yang merupakan rekomendasi dari pabrik pembuat sensor MQ3. Besar rentang tegangan keluaran rangkaian sensor MQ-3 diatur dengan menyesuaikan besar resistansi resistor variabel. 


\section{Perangkaian Alat Ukur Suhu dan Kadar Alkohol}

Alat ukur suhu dan kadar alkohol yang telah dibuat, tampak seperti gambar berikut

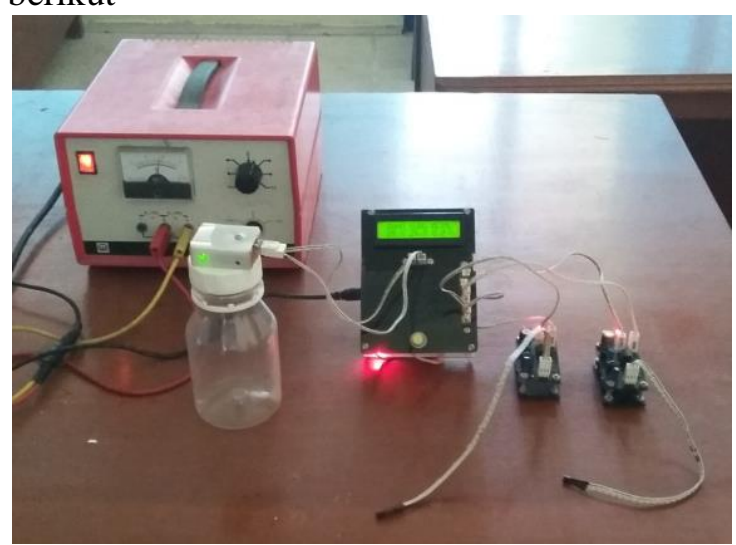

Gambar 9. Alat Ukur Suhu dan Kadar Alkohol

Catu daya sebagai sumber tegangan memberikan masukan tegangan sebesar $9 \mathrm{~V}$ yang kemudian dikonversi menjadi $4,8 \mathrm{~V}$ untuk kebutuhan tegangan input bagi mikrokontroler, sensor dan LCD, serta 3,0 V untuk tegangan referensi ADC mikrokontroler. ADC yang digunakan dalam pemrograman mikrokontroler memiliki resolusi 10 bit.

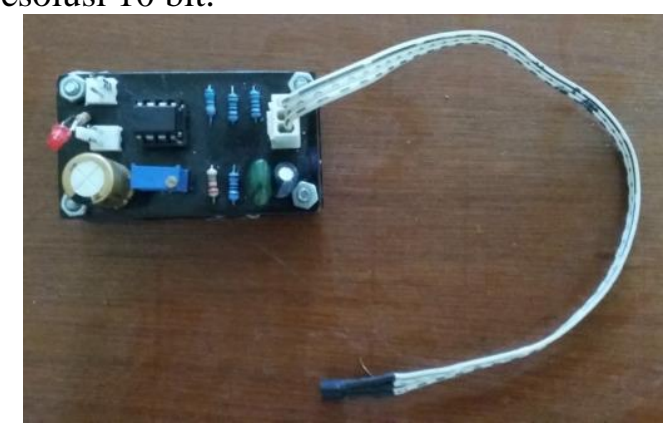

Gambar 10. Pengkondisi Sinyal Sensor Suhu LM35

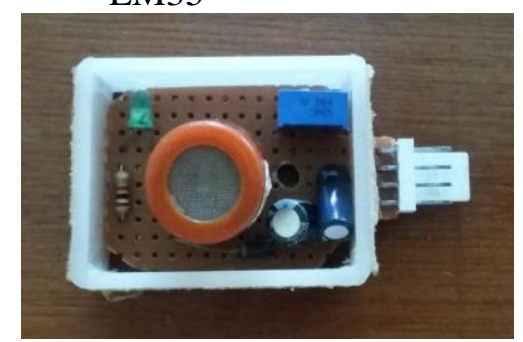

Gambar 11. Pengkondisi Sinyal Sensor Alkohol MQ-3

\section{Uji Pengukuran Suhu}

Pengujian pengukuran suhu oleh alat ukur suhu dilakukan pada rentang suhu $30^{\circ} \mathrm{C}$ sampai $100^{\circ} \mathrm{C}$ dengan memanaskan sensor suhu dan termometer sebagai alat ukur pembanding secara bersamaan menggunakan medium air yang dipanaskan dari suhu ruang hingga mendidih. Hasil pengukuran tampak pada tabel berikut.

Tabel 1. Perbandingan Pengukuran Suhu Menggunakan Alat Ukur Suhu dan Termometer

\begin{tabular}{|c|c|c|c|}
\hline No. & $\begin{array}{c}\mathrm{T} \\
\text { Termometer } \\
\left({ }^{\circ} \mathrm{C}\right)\end{array}$ & $\begin{array}{c}\text { T Alat } \\
\text { Ukur } \\
\text { Suhu } \\
\left({ }^{\circ} \mathrm{C}\right)\end{array}$ & $\begin{array}{c}\text { Selisih } \\
\left({ }^{\circ} \mathrm{C}\right)\end{array}$ \\
\hline 1 & 30,0 & 30,0 & 0,0 \\
\hline 2 & 35,0 & 34,9 & 0,1 \\
\hline 3 & 40,0 & 40,0 & 0,0 \\
\hline 4 & 45,0 & 45,0 & 0,0 \\
\hline 5 & 50,0 & 50,0 & 0,0 \\
\hline 6 & 55,0 & 54,9 & 0,1 \\
\hline 7 & 60,0 & 60,0 & 0,0 \\
\hline 8 & 65,0 & 64,9 & 0,1 \\
\hline 9 & 70,0 & 70,1 & 0,1 \\
\hline 10 & 75,0 & 74,7 & 0,3 \\
\hline 11 & 80,0 & 79,7 & 0,3 \\
\hline 12 & 85,0 & 84,6 & 0,4 \\
\hline 13 & 90,0 & 89,8 & 0,2 \\
\hline 14 & 95,0 & 95,0 & 0,0 \\
\hline 15 & 100,0 & 100,0 & 0,0 \\
\hline
\end{tabular}

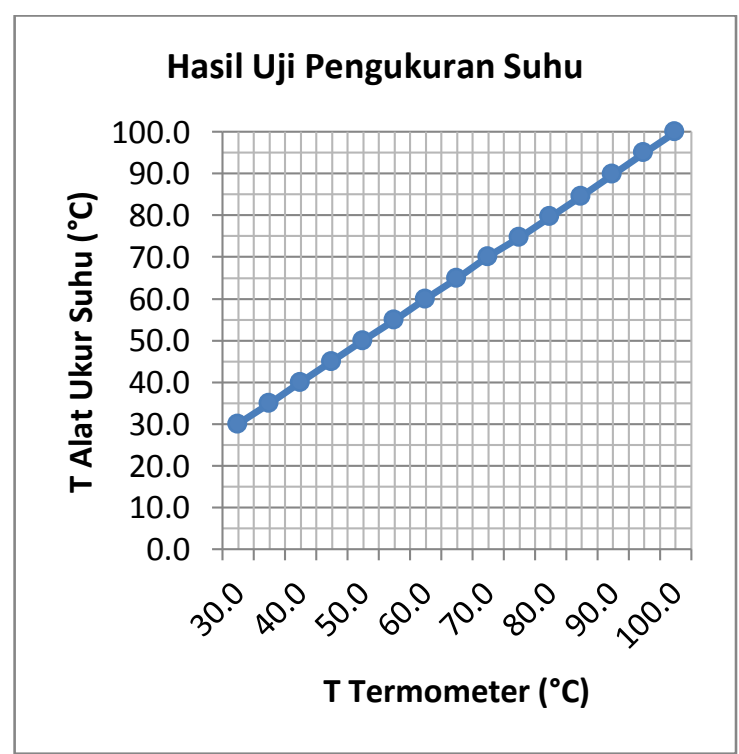

Gambar 12. Perbandingan Pengukuran Suhu Menggunakan Alat Ukur Suhu dan Termometer

Hasil pengukuran suhu menunjukkan bahwa hasil pengukuran suhu oleh alat ukur suhu hampir sama dengan hasil pengukuran 
menggunakan termometer pembanding dengan selisih maksimum sebesar $0,4^{\circ} \mathrm{C}$ dan nilai NRMSE 0,0028. Hasil pengukuran tersebut menunjukkan bahwa alat ukur suhu yang telah dibuat dapat mengukur perubahan suhu dengan akurasi yang sangat baik.

\section{Uji Pengukuran Kadar Alkohol}

Pengujian pengukuran kadar alkohol oleh alat ukur suhu dan kadar alkohol dilakukan dengan melakukan pengukuran terhadap alkohol dengan kadar yang berbedabeda. Kadar alkohol yang digunakan dalam pengujian diukur terlebih dahulu menggunakan alkoholmeter. Kemudian alkohol sebanyak $50 \mathrm{ml}$ dimasukkan ke dalam wadah berupa botol plastik, yang kemudian ditutup, dimana sensor telah diletakkan di penutup wadah. Hasil pengukuran kadar alkohol oleh alat ukur suhu dan kadar alkohol dicatat setiap menit, selama 30 menit. Terdapat 2 jenis cairan alkohol yang digunakan dalam percobaan, yakni alkohol medis dan alkohol hasil destilasi nira aren.

Data hasil uji pengukuran kadar alkohol medis tampak pada grafik berikut.

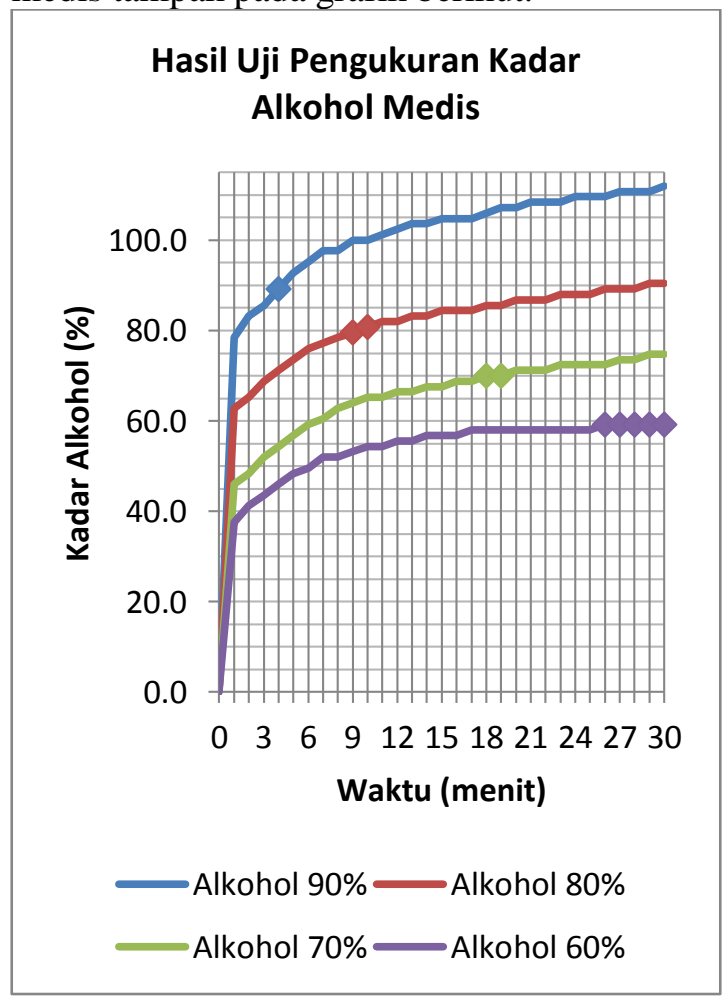

Gambar 13. Grafik Hasil Uji Pengukuran

Alkohol Medis

Dari hasil uji pengukuran kadar alkohol, pada pengukuran alkohol medis dengan kadar $90 \%$, nilai hasil pengukuran alat ukur kadar alkohol yang paling mendekati kadar sebenarnya pada menit ke 4 yakni menunjukkan nilai kadar alkohol sebesar $89,2 \%$. Pada pengukuran alkohol medis dengan kadar $80 \%$, hasil pengukuran alat ukur kadar alkohol menunjukkan nilai 79,6\% pada menit ke 9, dan menunjukkan nilai 80,8 \% pada menit ke 10. Pada pengukuran alkohol medis dengan kadar $70 \%$, hasil pengukuran alat ukur kadar alkohol menunjukkan nilai 70,0\% pada menit ke 20 sampai menit ke 21. Pada pengukuran alkohol medis dengan kadar 60\%, hasil pengukuran alkohol medis dengan alat ukur kadar alkohol menunjukkan nilai 59,2\% pada menit ke 26 hingga menit ke 30.

Data hasil uji pengukuran kadar alkohol hasil destilasi nira aren tampak pada grafik berikut.

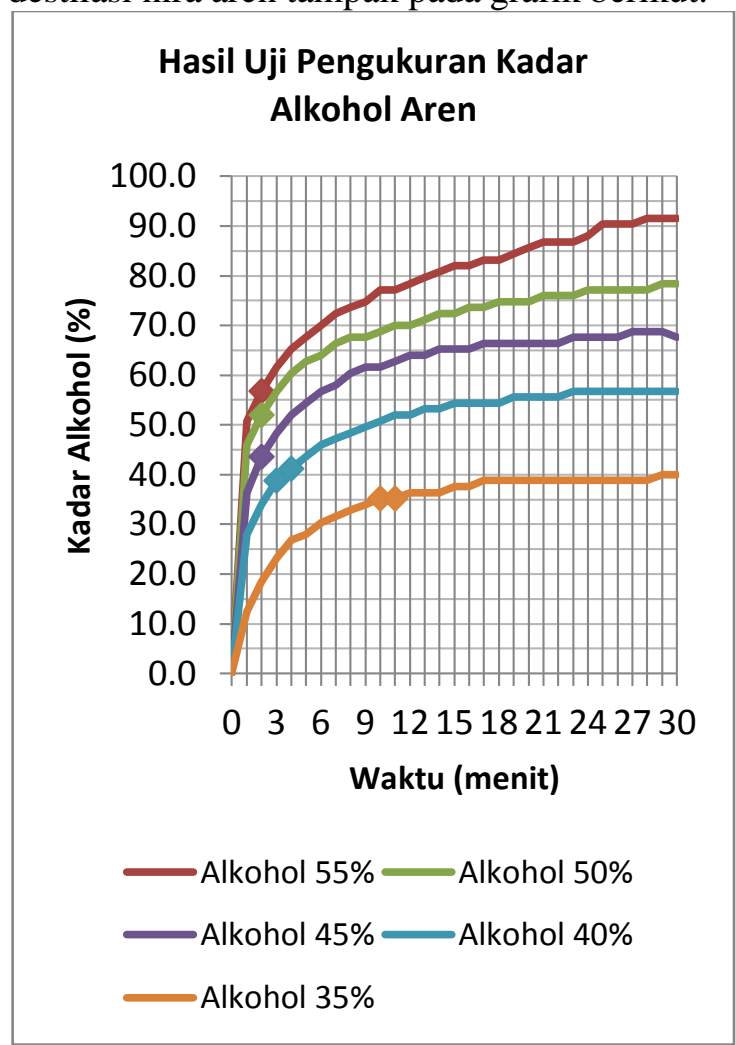

Gambar 14. Hasil Uji Pengukuran Alkohol Aren

Pada pengukuran kadar alkohol menggunakan alkohol hasil destilasi nira aren, pada pengukuran alkohol dengan kadar $55 \%$, alat ukur kadar alkohol menunjukkan nilai pengukuran yang paling mendekati kadar sebenarnya pada menit ke 2 yakni menunjukkan nilai kadar alkohol sebesar $56,8 \%$. Pada pengukuran alkohol aren dengan kadar 50\%, alat ukur suhu dan kadar alkohol menunjukkan nilai 52,0 pada menit ke 2 . Pada pengukuran alkohol aren dengan kadar 
$45 \%$, alat ukur suhu dan kadar alkohol menunjukkan nilai 43,6\% pada menit ke 2 . Pada pengukuran alkohol aren dengan kadar $40 \%$, alat ukur suhu dan kadar alkohol menunjukkan nilai $38,8 \%$ pada menit ke 3 dan menunjukkan nilai $41,2 \%$ pada menit ke 4. Pada pengukuran alkohol aren dengan kadar $35 \%$, hasil pengukuran pada menit ke 10 sampai menit ke 11 menunjukkan nilai $35,2 \%$.

\section{KESIMPULAN DAN SARAN}

\section{Kesimpulan}

Telah dirancang dan dibuat alat ukur suhu dan kadar alkohol menggunakan sensor LM35 dan sensor MQ-3. Alat ukur suhu dan kadar alkohol dapat mengukur perubahan suhu dengan akurat dengan nilai NRMSE 0,0028 dan dapat melakukan pengukuran kadar alkohol untuk alkohol medis dengan kadar $90 \%$ dalam waktu 4 menit, $80 \%$ dalam waktu 9 menit, $70 \%$ dalam waktu 20 menit dan $60 \%$ dalam waktu 26 menit dan dapat melakukan pengukuran kadar alkohol untuk alkohol hasil destilasi nira aren dengan kadar $55 \%, 50 \%$ dan $45 \%$ dalam waktu 2 menit, $40 \%$ dalam waktu 3 menit dan $35 \%$ dalam waktu 10 menit.

\section{Saran}

Perlu dilakukan pegujian pengaruh perubahan suhu dan kelembapan udara terhadap hasil pengukuran kadar alkohol.

\section{DAFTAR PUSTAKA}

Alciatore, D. G. and M.1 B. Histand. 2012. Introduction to Mechatronics and Measurement Systems. 4th edition. McGraw-Hill Inc., New York.

Atmel Corporation. 2013. ATMega8 Datasheet.

Bolton, W. 2006. Sistem Instrumentasi dan Sistem Kontrol. Terjemahan Soni Astranto. Gramedia, Jakarta.

Hanwei Electronics Co., Ltd. 2002. MQ-3 Datasheet.

Kister, H. Z. 1992. Distillation Design. McGraw-Hill Inc., New York.

National Semiconductor. 2000. LM35 Datasheet.

Placko, D. 2007. Fundamentals of Instrumentation and Measurement. ISTE, Newport Beach.
Satria, A. V. dan Wildan. 2013. Rancang Bangun Alat Ukur Kadar Alkohol Pada Cairan Menggunakan Sensor MQ-3 Berbasis Mikrokontroler AT89S51. Jurnal Fisika Unand. 2(1): 13-19. 